\title{
USE OF THE DEA METHOD TO VERIFY THE PERFORMANCE MODEL FOR HOSPITALS
}

\author{
Kristina Kocisova, Maria Hass-Symotiuk, \\ Magdalena Kludacz-Alessandri
}

\section{Introduction}

Global financial crisis influenced almost all sectors in national economies of individual countries, affecting the social sectors such as healthcare one significantly. In many countries, the health systems are mostly financed by public budget. Therefore the effective use of public money comes into attention, especially in crisis years (Androniceanu \& Ohanyan, 2016). Therefore performance measurement in the public healthcare system has become a more and more popular research challenge throughout Europe and the world. It is significantly associated with the global process of demographic ageing and increasing demands on health and social system in each country (Marešová et al., 2015a). Many types of research point to the urgency to solve this issue in the context of deepening disparities in health, nationally and internationally (Marešová et al., 2015b). According to (Šoltés \& Gavurová, 2014), the attention gets the efficiency of treating diseases with high prevalence, respectively the most financially demanding.

Proper assessment of hospital performance is essential for management decision-making, operational effectiveness, and strategy formulation (Gavurová et al., 2017; Ivlev et al., 2014). There are many opinions to the effect that a performance measurement system should be defined at the national or regional level of healthcare systems and published in a plan that clarifies the values and participation of various stakeholders (Shaw, 2003). In Poland are healthcare services mainly provided by the public sector. According to Hass-Symotiuk (2010), they are organised at the following three levels of the Polish healthcare management system: the central level (represented by the Ministry of Health), the regional level (represented by the regional governor, the marshal's office, and the regional offices of the National Health Fund) and the local level (represented by hospitals and their funding bodies).

It provides an interesting opportunity to examine and compare the relative performance of hospitals from different areas of this country. If there are performance differences between hospitals from different provinces, then there are important implications for public policy. This paper aims to measure and evaluate the productive efficiency of Polish hospitals at the regional (provincial) level using a Data Envelopment Analysis (DEA) methodology. This method has become more and more popular as a management tool used for performance evaluation of organisational structures.

DEA is a particular linear programming model for deriving the comparative efficiency of multiple-input and multiple-output of the Decision-Making Units (DMUs). We select a set of inputs and outputs for hospitals aggregated in 16 Polish provinces. For each hospital as the input variables, we considered two variables: Average time of hospitalisation (in days), and Average costs of day hospital treatment. The output variables included in the analysis are an Average number of patients per bed per year, Share of accredited hospitals as a proportion of the number of all hospitals, and Net profit per physician. The DEA models are solved using the computer program Frontier Analyst, Version 4 (Banxia Software, 2010). Frontier Analyst is a Windows-based efficiency analysis tool which uses the DEA method to examine the relative performance of organisational units which carry out the similar functions. It is recommended for use with public sector or "not for profit" organisations, such as hospitals. This program has been used in previous DEA studies for the evaluation of the efficiency of healthcare organisations (Zavras et al., 2002). In our empirical study, we will examine differences 
in technical efficiency at hospitals aggregated in Polish provinces because the demand for hospital services is based on geographic location (Gruca \& Nath, 2001). We expected that efficiency might be affected by differences in location; for example, hospitals from areas of low urbanisation could have too many beds for few patients and this could be a reason for lower efficiency. The obtained results offer rankings of Polish provinces related to the efficiency of their hospitals and allow to drawn some conclusions as to the dynamics of performance management.

\section{Literature Review}

Hospitals are the critical resource units in any healthcare system. They consume the majority of health resources and play the most crucial role in the delivery of healthcare services (Ersoy et al., 1997). Hospitals worldwide are increasingly the subject of analyses aimed at defining, measuring, and improving their performance. Development and use of a performance assessment framework for hospitals are considered as an effective way to ensure effective, high-quality service delivery and to identify unmet health needs, mobilise resources for improvement and achieve greater cost-effectiveness, while still meeting patient needs (Leggat et al., 1998). This increasing interest in measuring their productive performance has been observed since the mid1980s (Hollingsworth et al., 1999).

There are various approaches to the measurement of hospital performance. The most common is the balanced scorecard (BSC) tool developed by Kaplan and Norton at Harvard Business School in the early 1990s (Kaplan \& Norton, 1992). It provides comprehensive, balanced and, at the same time, minimised management information which is, however, still sufficient for multidimensional performance measurement.

The performance of hospitals can also be evaluated via the ratios. This method was used for example in the paper of Gapenski (2012). The indicators of efficiency measure the number of resources used to provide healthcare services. As a key input is considered the work, measured via Full-time equivalents, which is compared with other parameters.

The others method used to measure the efficiency in the healthcare sector are divided into the parametric and non-parametric methods. As the example of the parametric method can be mentioned Stochastic Frontier Approach (SFA). This method is very often used to measure efficiency in the health sector. Hofler and Rungeling (1994), Zuckerman et al. (1994) compared the efficiency of American hospitals, Vitaliano and Toren (1996) used SFA to assess the efficiency of New York hospitals, Linna et al. (1998) monitored Finish hospitals, Rosko (2001) measured the efficiency of hospitals in the US.

Within the group of the non-parametric method, the most often used is the Data Envelopment Analysis (DEA). DEA was used to compare national health systems in the paper of Al-Shammari (1999), Afonso and St Aubyn (2005), Bhat (2005), Hadad et al. (2013), Grausová et al. (2014) and Grausová and Hužvár (2016) between others. This method can also be used to evaluate the efficiency of the national health system (Kooreman, 1994; Ersoy et al., 1997; Parkin \& Hollingsworth, 1997; Gruca \& Nath, 2001; Jacobs, 2001; Kotsemir, 2013), the efficiency of hospitals and so on. DEA has already been used by researchers to evaluate the efficiency of various organisational forms in the healthcare industry including teaching hospitals (Sherman, 1986), nursing services (Nunamaker, 1983), nursing homes (Nyman \& Bricker, 1989), physicians, and health maintenance organisations (Nayar \& Ozcan, 2008).

One of the initiatives undertaken in Poland was to develop and implement a system for measuring the performance of Polish healthcare.

This question was carried out by a team from the Chair of Cost Accounting at the University of Szczecin represented by Hass-Symotiuk (2010) within a research project conducted within a grant from the Polish Minister of Science and Higher Education, entitled "Conception of hospital reporting for an integrated system of performance assessment". The objective of the project as a whole was to develop selected groups of indicators relevant for integrated performance measurement and assessment system designed for public hospitals. One of the main achievements of this research project was to develop a general theoretical model for performance measurement in Polish hospitals as well as the healthcare system as a whole. Because the hospital system is the most significant component of the health system, it 
can be said that to a high degree, the efficiency of the hospital system determines the health system's efficiency (Štefko et al., 2016).

The final framework of the Polish model focuses on four priority areas (dimensions): patients, internal processes, development, and finance. The model also includes a fifth area of assessment that reflects the needs of various stakeholders representing the three levels of the healthcare management system (KludaczAlessandri, 2016):

- central level, represented by the Ministry of Health (the macroeconomic perspective of assessment),

- the regional level, represented by the governor, the marshal's office, and the regional offices of the National Health Fund (the mesoeconomic perspective of assessment),
- the local level, represented by hospitals and their funding bodies (the microeconomic perspective of assessment).

Fig. 1 presents the structure of the developed model. The essence of the performance model is to simultaneously present and analyse the hospital's achievements in four dimensions of evaluation: patients, internal processes, development, and finance. All of these dimensions are important from three perspectives: microeconomic, mesoeconomic, and macroeconomic, all of which have been taken into account during the development of a set of indicators for various kinds of stakeholders: hospital managers and hospital owners, the governor, the National Health Fund, and the Ministry of Health (KludaczAlessandri, 2016).

This performance model can be recognised as a multidimensional construct, requiring

\section{Fig. 1: The conceptual performance model for the Polish healthcare system}

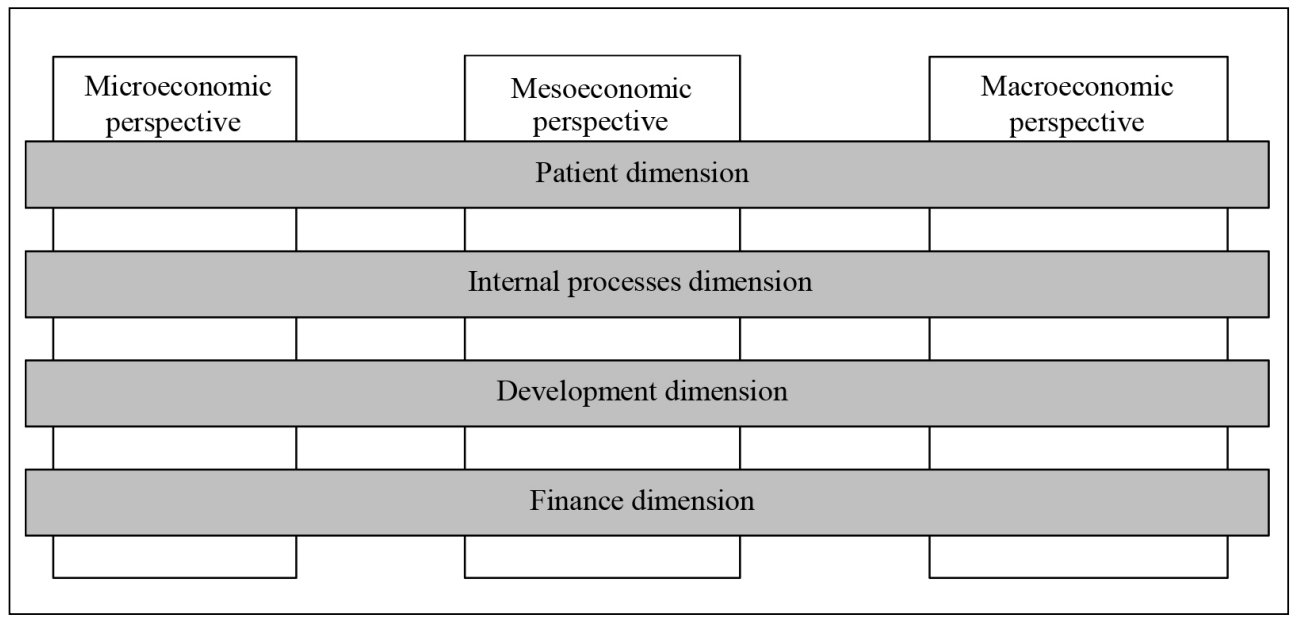

Source: Kludacz-Alessandri (2016), Kludacz (2012), Hass-Symotiuk (2010)

some indicators to enable a full assessment of individual hospitals and healthcare systems at regional and national level. We can define the performance indicators as observations expected to indicate certain aspects of performance by providing data that is either numerical or qualitative. Furthermore, they are evaluative, results-oriented and they include a reference point so that current achievement can be compared to earlier performance or another standard (Leggat et al., 1998). We based the model on the assumption that the selected indicators should measure whether the goals specified for all dimensions and all three levels of the health management system were realised.

The construction of the performance measurement model for Polish hospitals, as well as for the whole healthcare system, was realised in four stages: 1) defining the 
dimensions of performance measurement that were relevant to the specific operations in hospitals and the other stakeholders. 2) determining a universal set of targets for individual stakeholders to be implemented at three levels of the healthcare management system (micro, meso, and macro). 3) selecting indicators for each dimension and performancemeasurement level. 4) verification of the proposed performance model. This article aims to present the results of the last stage of the research project - verification of the proposed concept of a performance model using the Data Development Analysis (DEA). The previous three stages of the project have already been presented in the literature (Kludacz-Alessandri, 2016; Kludacz, 2012; Hass-Symotiuk, 2010).

\section{Methodology}

The value of the performance model developed by the authors is reflected in the possibility of using it not only in individual hospitals but also in hospital benchmarks in order to compare their performances and prepare the rankings. Analysis of the performance data resulting from use of the performance model can be done in a variety of ways; the method that can be used to conduct comparative analyses and prepare rankings of hospitals at both the meso and macro level, using the indicators from different dimensions of the performance model, is the DEA method (Data Envelopment Analysis). In this study, DEA was used at the meso level to provide healthcare organisers with information regarding relatively best practice provinces in the observation set and locate relatively inefficient provinces by comparison with provinces indicating best practice. Additionally, it indicates the magnitude of these inefficiencies.

DEA is a non-parametric technique which is used to compare the relative efficiency of homogeneous sets of units (Barrientos \& Boussofiane, 2005). It is a linear programming model, assuming no random mistakes, used to calculate the technical efficiency of a given organisation relative to the performance of other organisations producing the same goods or services, e.g. healthcare organisations with multiple incomparable inputs and outputs.

The method uses linear programming techniques in the estimation of frontier functions. It was developed by Charnes et al. (1978) based on earlier work by Farrell (1957). It was initially developed to compare the technical efficiency of the public sector (Charnes et al., 1978), and has been applied successfully to the healthcare sector (Fizel \& Nunnikhoven, 1992; Kooreman, 1994; Parkin \& Hollingsworth, 1997; Chirikos \& Sear, 2000).

Utilising selected variables such as input and output, DEA searches for the points with the lowest input variable for any given output, connecting these points to form the efficiency frontier. This frontier indicates the best relationship between inputs and outputs. This method also allows the identification of the sources and level of effectiveness for each input and output.

DEA allows measurement of technical efficiency, which implies the maximum possible outputs (effects, results, and so on) from a given set of inputs (reasons, outlays, resources used, and so forth), or produces a given output with the minimum quantity of inputs. Within the context of healthcare services, technical efficiency may then refer to the physical relationship between the resources used (e.g. capital, labour, and equipment) and some-or-other health outcome that may be defined in terms of intermediate outputs (e.g. number of patients treated, patient-days, waiting time) or a final health outcome (lower mortality rates, longer life expectancy, etc.) (Palmer \& Torgenson, 1999; Worthington, 2004). Thus, when a hospital is technically efficient, it operates on its production frontier, and the efficiency of other hospitals in the sample is defined relative to these best performers.

Mathematically, DEA determines the best weights for each input and output for a particular unit under study to maximise its relative efficiency (Ivlev et al., 2014). It is justifiable to apply the DEA method to a group of objects to which data matrixes have been ascribed using multiple specifying inputs and multiple outputs. The DEA method is non-parametric. Therefore, it is not necessary to know the values of the weight coefficients which are determined for each object in the optimisation process. In this way, it is possible to avoid subjectively ascribing values to these coefficients, something which frequently occurs in other methods. There is no need to set a weight for each variable but only to consider the mathematical relationships of the variables. The DEA model can include multiple outputs and inputs without requiring explicit specification of functional relations between inputs and outputs (as in regression 
approaches). It computes a scalar measure of efficiency and determines adequate levels of inputs and outputs for the objects under evaluation (Bowlin, 1998). Thus, such a measure of the efficiency of an object is a function of weights $\mu$ and $v$ (Gierulski, 2010).

In this study, efficiency in DEA is defined as the ratio of the weighted sum of outputs of Polish Provinces to its weighted sum of inputs. Given $s$ outputs and $m$ inputs, efficiency for province $q$ is defined as follows:

$$
\begin{aligned}
& \operatorname{Max} \frac{\sum_{r=1}^{s} u_{r} y_{r q}}{\sum_{i=1}^{m} v_{i} x_{i q}} \\
& \text { S.t. } \quad \frac{\sum_{r=1}^{s} u_{r} y_{r j}}{\sum_{i=1}^{m} v_{i} x_{i j}} \leq 1 \quad j=1, . ., n \\
& u_{r} \geq 0 \quad v_{i} \geq 0 \quad r=1, . ., s \quad i=1, . ., m
\end{aligned}
$$

where: $y_{r q}$ - quantity of $r^{\text {th }}$ output $(r=1,2, \ldots, s)$ for province $q ; x_{i q}$ - quantity of $i^{\text {th }}$ input $(i=1,2, \ldots, m)$ for province $q ; y_{r j}$ - quantity of $r^{\text {th }}$ output $(r$ $=1,2, \ldots, s)$ for province $j(j=1,2, \ldots, n) ; x_{i j}-$ quantity of $i^{\text {th }}$ input $(i=1,2, \ldots, m)$ for province $j$ $(j=1,2, \ldots, n) ; \mu_{r}$ - weight attached to $r^{\text {th }}$ output $(r=1,2, \ldots, s) ; v_{i}-$ weight attached to $i^{\text {th }}$ input $(i=1,2, \ldots, m)$.

Since the weights are not known a priori, they are calculated from the efficiency frontier by comparing a particular province with others producing similar outputs and using similar inputs, known as the object peers. DEA computes all possible sets of weights which satisfy all constraints and chooses those which give the most favourable view of the province that has the highest efficiency score. The objective of each object is to maximise this ratio subject to its technological constraints. When this maximum is attained, $e=1$ and when, not technical efficiency $(T E)<1$.

By using DEA, inefficient objects can be determined, and corrective measures are taken. Advantages and limitations of the DEA method are presented in Tab. 1.

One of the advantages of the DEA method is the ability to manage complex environments with multiple inputs and output technologies, like hospitals, but as a non-statistical method, it is not able to generate the usual diagnostic tools to judge the goodness-of-fit of the model specifications produced (Jacobs, 2001).

The DEA method focuses on individuals rather than on the average. It has a unique advantage when investigating the differences in an individual decision-making unit (especially the Decision-Making Unit, DMU) on performance and relative efficiency (Yu, 2014). The DEA method can also identify which inputs are over-utilised or which outputs are underproduced for each non-efficient DMU.

DMUs can refer to the collection of organisations, departments, divisions or administrative units with the same goals and objectives, and which have common inputs and outputs. Examples of DMUs include hospitals, schools, courts, banks, and so on (Al-Shammari, 1999). In our study, an individual Polish province represents a single DMU. The efficiency of a DMU is computed relative to other DMUs, not on an absolute basis. An efficiency score is computed for each DMU based on its achieved ratio of outputs to inputs and the best obtainable ratio in the sample.

The relative efficiency score of a DMU can reach a value between 0 and 1 , or given as a percentage $(0 ; 100 \%)$. The value 1 indicates a relatively efficient DMU and a value less than 1 shows an inefficient DMU (Duguleana \& Duguleana, 2015). It means that it is possible to make better use of resources and thus improve the efficiency without the need to increase them. This efficiency score varies and depends on the input and output variables used as factors.

Underlying assumptions of DEA are that all DMUs have similar strategic objectives and use the same kind of inputs, producing the same kind of outputs. DEA measures the efficiency of DMUs that have the same goals and objectives. The assumptions of this method are as follows:

1. There are $n$ objects (Decision Making Units - DMUs) to be analysed.

2. To express the efficiency in numbers we have to have quantifiable (numeral) values of inputs and outputs at our disposal, so each DMU uses $m$ inputs to produce $s$ outputs.

3. The primary condition for performing of the DEA method is a file of homogenous units with the same objective function.

4. The inputs and outputs must be defined in the same way for the same DMU.

Traditionally, DEA models have also 


\section{Tab. 1: Advantages and limitations of the DEA method}

\begin{tabular}{|c|c|}
\hline Advantages & Limitations \\
\hline $\begin{array}{l}\text { DEA method can be used for forecasting the } \\
\text { efficiency scores of the objects. } \\
\text { DEA method evaluates changes in input and } \\
\text { output variables needed for reaching the } \\
\text { efficiency frontier. } \\
\text { In DEA models user can take into account } \\
\text { external factors (in the form of environmental } \\
\text { variables). } \\
\text { - Input and output variables can be expressed in } \\
\text { different units. } \\
\text { - The flexibility of the model in accommodating } \\
\text { different sets of inputs and outputs. } \\
\text { - k key advantage of DEA is that no weights are } \\
\text { needed for the inputs and outputs. } \\
\text { - The standardisation provided by the } 0-1 \text { scale, } \\
\text { respectively the } 0-100 \% \text {. } \\
\text { The robustness of the linear programming } \\
\text { method. } \\
\text { DEA indicators can be used to 'uncover } \\
\text { determinants of inefficiency' by comparing the } \\
\text { input/output mixes of efficient and inefficient } \\
\text { objects, making DEA a useful tool for targeting } \\
\text { resources to be used most efficiently. }\end{array}$ & $\begin{array}{l}\text { - Results are sensitive to the number of selected } \\
\text { inputs and outputs and the sample size - small } \\
\text { sample size and overly broad set of input and } \\
\text { output variables seriously bias the efficiency } \\
\text { scores; Sample size should be similar to the } \\
\text { requirements for the regression analysis - } \\
\text { generally from } 4 \text { to } 15 \text { units for each variable. } \\
\text { In literature it was defined that the optimal } \\
\text { value of inputs }(m) \text { and outputs }(s) \text { in DEA } \\
\text { models should be lower than the number }(n) \text { of } \\
\text { analysed Decision-Making Units divided by } 3 \text {, } \\
\text { which can be written as follow: ( } m+s) \leq n / 3 \text {. } \\
\text { DEA efficiency scores can be severely } \\
\text { influenced by the content of the sample (when } \\
\text { adding each new object of analysis, it is } \\
\text { necessary to recalculate the entire model); } \\
\text { they are also sensitive to incorrect data. } \\
\text { Is sensitive to outliers. } \\
\text { DEA is based on extreme points and compares } \\
\text { each unit to the best performers. This particular } \\
\text { feature makes the DEA analysis more sensitive } \\
\text { to data noise and measurement errors, } \\
\text { whereas parametric techniques like stochastic } \\
\text { frontier analysis allow for statistical noise. } \\
\text { It does facilitate an estimate of "relative" } \\
\text { efficiency of a selected unit within a group but } \\
\text { stops short of estimating absolute efficiency. }\end{array}$ \\
\hline
\end{tabular}

Source: Berg (2010), Kotsemir (2013), Olatubi and Dismukes (2000), Fare et al. (2004)

required the assumption that all input and output values be non-negative, while in more recent literature (Emrouznejad et al., 2008) there have been various approaches put forward for dealing with negative data, e.g. loss when net profit is an output variable (Emrouznejad et al., 2010). Efficiency is always a relative quantity; efficiency as a concrete value has its information value only when compared with the efficiency of other objects. Without this comparison, there is no appropriate information value.

\section{Data Description and Results of DEA Analysis}

The DEA method was used for the comparative analysis of hospital performance indicators. This analysis has been performed taking into account four dimensions of hospital performance:
1. patient dimension,

2. internal processes dimension,

3. development dimension,

4. finance dimension.

The analysis was carried out from the meso perspective as the calculations were based on data aggregated at the regional (provincial) level. At this level, the organisers of healthcare systems represented by the regional governor, the marshal's office, and the regional offices of the National Health Fund are interested mostly in the realisation of functions related to the strategic and operational management of mid-level healthcare systems (implementation of national plans in the region, the study of the health needs of the population in the region, and the coordination of the work of local institutions).

The most critical part of DEA is the selection and definition of proper input and output 
indicators. Due to the small number of objects in this study (16 provinces), the model includes only five variables. It is in line with the condition of DEA model that the number of inputs $(m)$ and outputs $(s)$ in DEA models should be lower than the number $(n)$ of analysed Decision-Making Units divided by 3 . The indicators selected for analysis are presented in Fig. 2.
The output variables were represented by an Average number of patients per bed per year, Share of accredited hospitals as a proportion of the number of all hospitals, and Net profit per physician. Input variables included Average time of hospitalisation (in days), and Average costs of day hospital treatment.

\section{Fig. 2: The indicators selected to the analysis}

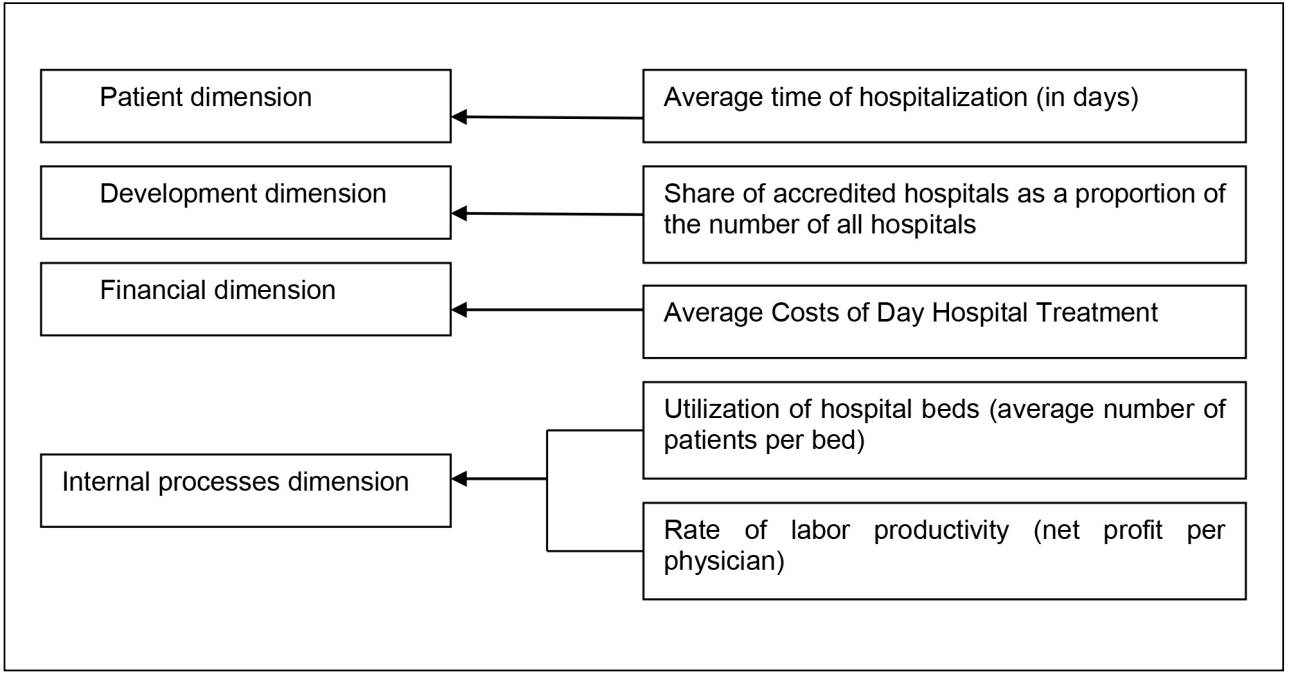

The limited number of input and output indicators is a result of the fact that DEA operates more powerfully when the number of DMUs exceeds the number of the combined total of inputs and outputs by at least two times (Drake \& Howcroft, 1994).

The sample for this study included Polish hospitals from all 16 Polish provinces, and so all 16 Polish provinces were considered as DMUs of a DEA. The input and output variables are the same for all DMUs. The data upon which this study was obtained are from the annual Statistical Bulletin published by the Ministry of Health. This bulletin is published annually by the Centre for Health Information Systems and contains administrative, operational, and clinical information on the majority of Polish healthcare organisations, e.g. detailed information on the number of hospitals and medical personnel for each Polish province. The calculation results for Polish provinces are presented in Tab. 2.

The aim of DEA is not only to determine the efficiency rate of the units reviewed but in particular to find target values for input and output variables for an inefficient unit. This method also allows determining of (Guzik, 2009):

1. Efficient and inefficient objects.

2. Ranking of objects.

3. The optimal technology.

4. Practical benchmarks for inefficient objects.

5. Type of scale economies.

DEA enables measurement of the performance of each DMU relative to the performance of all other DMUs, rather than against an idealised standard of performance. In this study, DEA allowed a comparison of the relative efficiency of Polish provinces by determining 


\begin{tabular}{|c|c|c|c|c|c|c|}
\hline No. & Polish provinces & $\begin{array}{c}\text { Average } \\
\text { time of hospitali- } \\
\text { sation } \\
\text { (days) }\end{array}$ & $\begin{array}{l}\text { Average costs } \\
\text { of hospital tre- } \\
\text { atment (PLN) }\end{array}$ & $\begin{array}{l}\text { Average number } \\
\text { of patients per } \\
\text { bed per year } \\
\text { (persons) }\end{array}$ & $\begin{array}{c}\text { The share } \\
\text { of accredited } \\
\text { hospitals } \\
(\%)\end{array}$ & $\begin{array}{l}\text { Net profit per } \\
\text { physician } \\
\text { (PLN) }\end{array}$ \\
\hline 1 & Lower Silesia Province & 5.1 & 429.2 & 49.8 & 8.3 & 24.3 \\
\hline 2 & Kujawy-Pomerania Province & 5.7 & 506.9 & 41.6 & 11.1 & 14.8 \\
\hline 3 & Lublin Province & 6.7 & 368.2 & 41.8 & 16.2 & 13.5 \\
\hline 4 & Lubuskie Province & 5.9 & 499.6 & 42.3 & 9.5 & 62.9 \\
\hline 5 & Łódź Province & 6.1 & 409.3 & 43.0 & 1.7 & 9.9 \\
\hline 6 & Małopolska Province & 6.3 & 429.0 & 42.7 & 16.4 & 12.9 \\
\hline 7 & Mazovia Province & 5.9 & 473.7 & 44.2 & 11.4 & -12.8 \\
\hline 8 & Opole Province & 6.2 & 519.3 & 41.5 & 25.0 & 18.8 \\
\hline 9 & Podkarpacie Province & 5.9 & 537.1 & 45.1 & 25.0 & -16.5 \\
\hline 10 & Podlasie Province & 5.9 & 432.5 & 43.4 & 3.4 & 0.5 \\
\hline 11 & Pomerania Province & 5.3 & 502.9 & 45.8 & 13.5 & 5.7 \\
\hline 12 & Silesia Province & 7.0 & 375.1 & 36.2 & 11.3 & -5.5 \\
\hline 13 & Świętokrzyskie Province & 5.5 & 573.9 & 47.1 & 36.4 & -5.6 \\
\hline 14 & Warmia-Masuria Province & 5.3 & 492.6 & 46.4 & 34.3 & 10.9 \\
\hline 15 & Wielkopolska Province & 5.2 & 439.0 & 47.7 & 5.0 & -2.1 \\
\hline 16 & West Pomerania Province & 5.8 & 431.9 & 42.5 & 16.7 & 14.2 \\
\hline
\end{tabular}

Source: own work

efficient Provinces as benchmarks and by measuring the inefficiencies in input combinations in other Provinces relative to the benchmark. The efficiency score is the ratio between the sum of weights multiplied by corresponding outputs and the weighted sum of inputs. They are expressed in percentages to see the relative efficiency of provinces better. The structure of effective and ineffective objects is shown in Fig. 3 .

The object being evaluated can be judged as relatively inefficient if the other object requires less input to obtain the output achieved by the object being evaluated, or judged relatively efficient if the composite object requires as much input as the object being evaluated. The DEA results identified comparatively efficient best-practice provinces $($ score $=1$ ) and relatively inefficient provinces (score $<1$ ). An efficiency score of 1.0 implies that this province is as efficient as any linear combination of provinces in the sample. Efficiency scores less than one implies that these provinces can improve their efficiency by increasing outputs and/or decreasing inputs.

The distribution of the inefficient provinces over efficiency scores ranged from 0.762 to 0.939 , respectively from $76.2 \%$ to $93.9 \%$. The outcomes anticipated as a result of the analysis include:
- Five highly effective provinces with an efficiency rate of $100 \%$ : Lower Silesia Province, Lublin Province, Lubuskie Province, Świętokrzyskie Province, Warmia-Masuria Province.

- One province with an efficiency rate between 91 and 99.9\%: Wielkopolska Province, with an efficiency rate of $93.9 \%$.

- Nine provinces with an efficiency rates between 81 and 90\%: Pomerania Province (90.8\%), West Pomerania Province $(90.8 \%)$, Łódź Province (90.5\%), Małopolska Province (90.5\%), Podlasie Province (86.5\%), Podkarpacie Province (84.4\%), Silesia Province (84.4\%), Opole Province (84.2\%), Mazovia Province (82.8\%).

- One relatively most-inefficient province with an efficiency rate between 71 and $80 \%$ : Kujawy-Pomerania Province (76.2\%).

Efficient provinces are using fewer inputs to produce more outputs compared to inefficient provinces. The Kujawy-Pomerania Province achieved the lowest result. The $76.2 \%$ efficiency score of this province tells us that efficient provinces can obtain at least the level of each output that Kujawy-Pomerania Province obtains by having available no more than $76.2 \%$ of input resources required by hospitals from Kujawy-Pomerania Province. It also means 


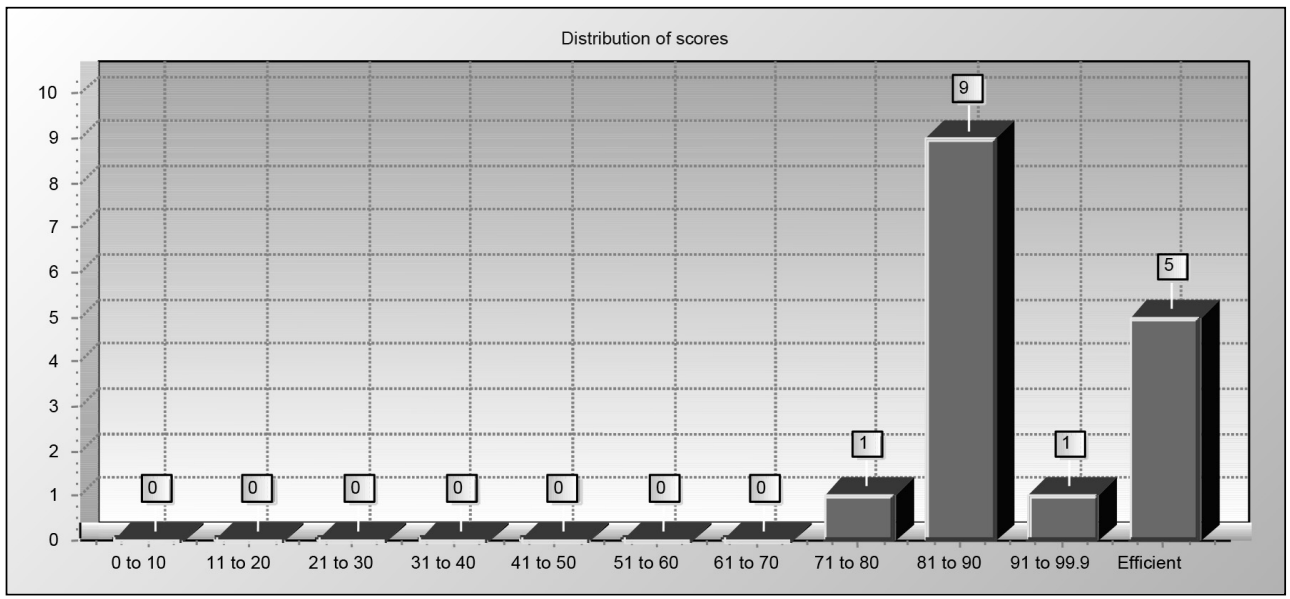

Source: own work

\section{Fig. 4: Ranking of provinces regarding efficiency}

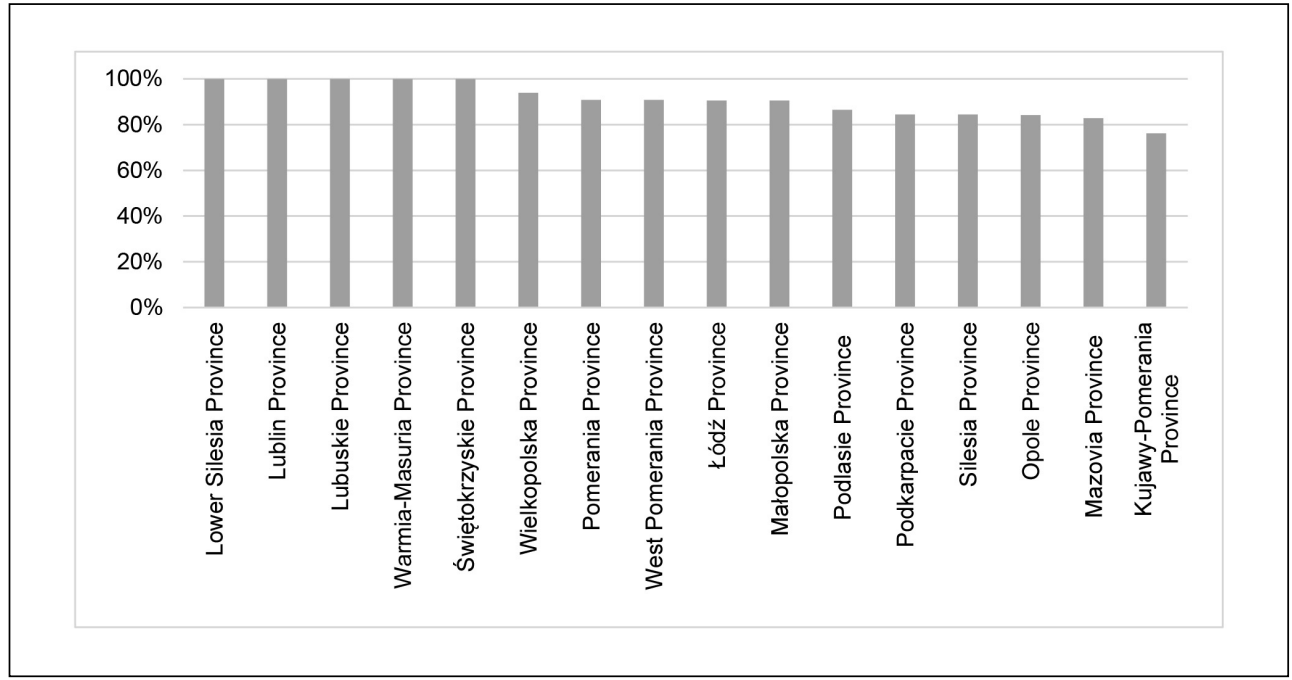

Source: own work

that hospitals from Kujawy-Pomerania Province should be able to achieve its actual output level using, on average, about $23.8 \%$ less of each input.

Analysis based on the DEA method makes it possible to indicate which objects have the highest efficiency (those classified highest on the rating list) and then compare the remaining objects with the "best" ones, which constitutes a certain kind of benchmarking (Gierulski, 2010). It means that the DEA method allows us to compute the so-called benchmarking 
formulas for inefficient units. A benchmark is understood as an indication of specific efficient units whose example ought to be followed in order to improve present efficiency (Kucharski, 2015). Ranking of provinces regarding efficiency is presented in Fig. 4.

The efficient units in DEA are the most efficient of those observed, not in comparison to some ideal. Thus, the DEA efficient group is that subset demonstrating the "best practices" among a group of operating units (Rosenmayer, 2014). Inefficient provinces (DMUs) should be compared to those provinces demonstrating superior performance. The benchmark provinces are shown in Fig. 5.

Benchmark provinces show the best practices for improving efficiency. The most efficient province is Lower Silesia Province, which is considered as the benchmark for ten provinces. It can, therefore, be said that ten provinces could find the best practices of Lower Silesia Province. Lower Silesia Province is thus a region that should be a benchmark for the other provinces that are not fully effective. So, it is a benchmark for the following provinces: Kujawy-Pomerania, Małopolska,
Mazovia, Podkarpacie, Podlasie, Pomerania, Wielkopolska, West Pomerania, Silesia and Łódź. Warmia-Masuria Province is a benchmark for provinces such as Kujawy-Pomerania, Małopolska, Mazovia, Opole, Podkarpacie, Pomerania and West Pomerania. Lublin Province is a benchmark for provinces such as Małopolska, Mazovia, Opole, West Pomerania and Silesia. Lubuskie Province is a benchmark for Opole Province. Świętokrzyskie Province, despite full effectiveness, is not a benchmark for any of the other provinces.

One of the advantages of the DEA method is that it brings recommendations how to modify input and outputs variables to reach the efficiency frontier. Optimal values of inputs and outputs could be calculated through values of benchmark provinces.

Analysis of optimal technology was carried out in the example of the Kujawy-Pomerania Province, where hospitals have excess inputs or insufficient outputs compared to those provinces on the efficiency frontier. As a result of this analysis, it seems that the benchmark for Kujawy-Pomerania Province should be the Lower Silesia and Warmia-Masuria Provinces.

\section{Fig. 5: Benchmark provinces}

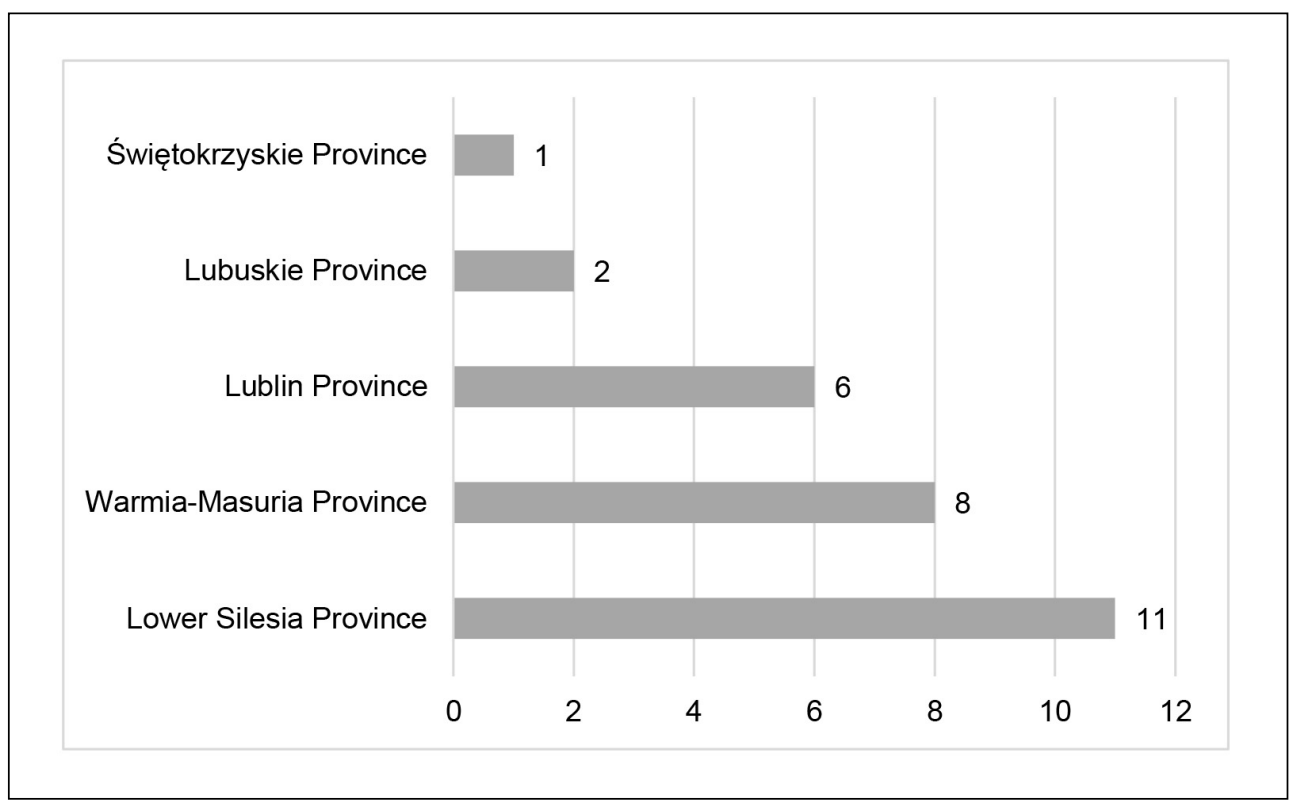


The potential improvement of the Kujawy-Pomerania Province

\begin{tabular}{l|r|r|r}
\multicolumn{1}{c|}{ Variable } & Actual value & Optimum value & $\begin{array}{c}\text { Potential } \\
\text { improvement }\end{array}$ \\
\hline Average costs of day hospital treatment & 506.9 & 373.07 & $-26.40 \%$ \\
\hline Average number of patients per bed & 41.6 & 41.60 & $0.00 \%$ \\
\hline The average time of hospitalisation in days & 5.7 & 4.35 & $-23.75 \%$ \\
\hline The share of accredited hospitals & 11.1 & 11.10 & $0.00 \%$ \\
\hline Net profit per physician & 14.8 & 18.46 & $24.71 \%$ \\
\hline
\end{tabular}

Source: own work based on the results of DEA analysis.

Note: Comparison of the Lower Silesia and Warmia-Masuria Provinces

\section{Fig. 6: Potential improvement}

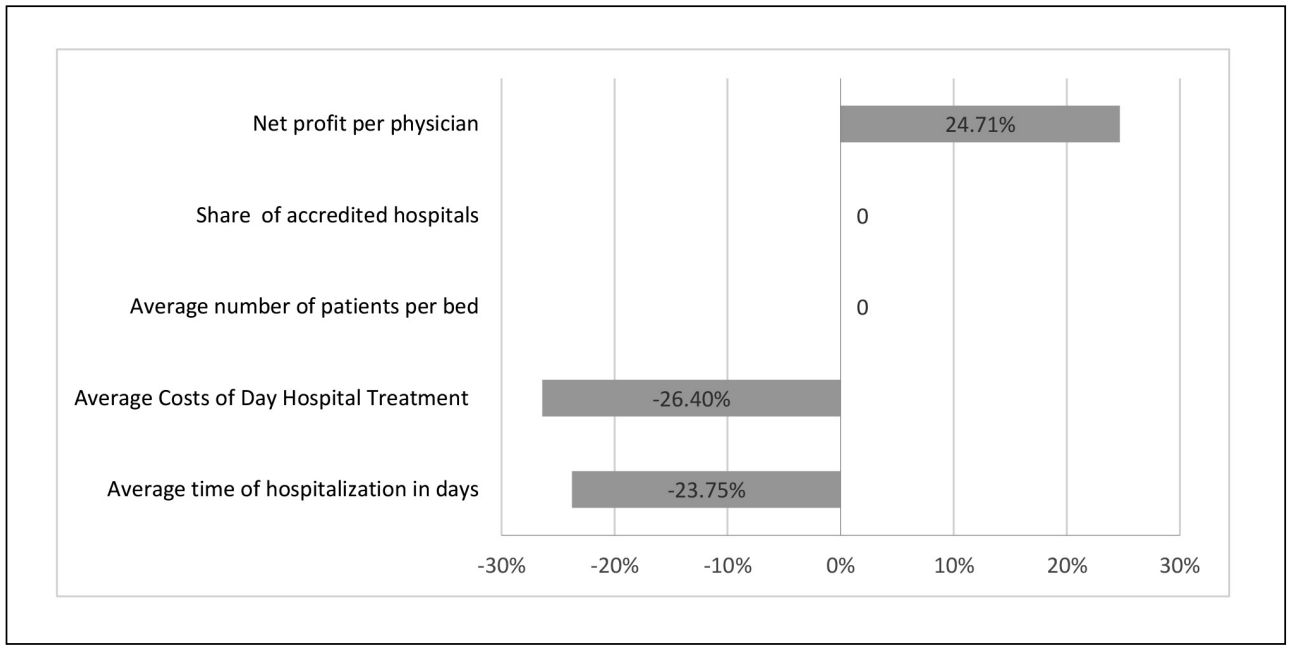

Source: own work

Detailed results are presented in the following table (Tab. 3) and figure (Fig. 6). By our analysis and according to the optimal values of input and output variables we can say that Kujawy-Pomerania Province should reduce the input variable Average costs of day hospital treatment by $26.4 \%$ and input variable Average time of hospitalisation in days by $23.75 \%$. On the other hand, on the output side, it should be modified only in case of Net profit per physician, which should be increased by $24.71 \%$.

This study is one of the first attempts at analysing the technical efficiency of hospital service in individual provinces in Poland by using DEA methodology. The study illustrates that a vast majority of hospitals in Polish provinces run inefficiently. As a hospital system is the most significant component of the health system, we can say, that the efficiency of the hospital system determines the efficiency of the whole healthcare system. As we can see on the example of Kujawy-Pomerania Province, the inputs are wasted and not utilised in the right production of hospital services. According to our findings which are in line with findings in the study of Ersoy et al. (1997), we can say, that with this information manager should be able to make educated choices on which path to 
take to increase the efficiency of their hospitals. Since hospital managers generally have more control over their inputs, they may devote more attention to the examination of total inefficiencies generated by excessive input usage. However, examinations of outputs inefficiencies can also provide strategic direction for the hospital by indicating where to increase its efficiency.

\section{Conclusion}

Performance information in healthcare can be used for many purposes, for example, to improve organisational effectiveness (to clarify and communicate organisational goals and priorities to managers and employees, in benchmarking), ensure accountability (political, economic, clinical or patient, and community.), monitor management, and foster collaboration among institutions and other stakeholders (Leggat et al., 1998). The results of efficiency measurements are the starting point in improving healthcare systems.

The objective of this study was to analyse the efficiency of Polish hospitals aggregated at the provincial level to enable performance assessments for this level of the Polish healthcare system. Data Envelopment Analysis (DEA), a non-parametric, multiple inputs, multiple output technique, was used to examine hospital performance. The study attempted to find out which provinces can be used as models and illustrated the areas where inefficient units need to be improved.

The result of this study was to develop a mechanism for assessing the efficiency of Polish hospitals that might be used to design and build a regional performance assessment system of public hospitals. This study allowed identification of the provinces with relatively efficient hospitals, the provinces with relatively inefficient hospitals, and the efficiency reference set for the provinces with relatively inefficient hospitals. For inputs, we considered the average time of hospitalisation (in days), and Average Costs of Day Hospital Treatment. As output variables, we considered an average number of patients per bed per year, the share of accredited hospitals as a proportion of the number of all hospitals, and net profit per physician. After using the DEA method with Frontier Analyst, Version 4 (Banxia Software, 2010), we found the following results: 5 provinces are efficient, and 11 are not efficient. The efficiency score varies from $76.2 \%$ to $100 \%$. Provinces such as Lower Silesia
Province, Lublin Province, Lubuskie Province, Świętokrzyskie Province, and Warmia-Masuria Province were the best performers in that they maximised both quantitative and qualitative outcomes.

The basic framework for equitable resource allocation must be designed centrally by policy-makers and must give broad guidelines to regional and local authorities. Thus, DEA is a beneficial technique for hospital administrators seeking to identify opportunities for performance improvement, e.g. through benchmarking. Benchmarking of performance indicators enables identification of units that consistently produce the best results over extended periods of time. It can help hospitals or systems to become more productive by focusing on the best practices and identifying issues that require further attention.

DEA applies to a comparative analysis of hospitals and their grouping according to a performance from various perspectives of the healthcare sector. It is a powerful, comprehensive, and efficient mechanism that, in this study, has been utilised for assessing the efficiency of Polish hospitals aggregated at the regional level in 16 provinces. Besides, efficient provinces can be seen as benchmarks whose results can be observed as target values. Furthermore, it can also be used at a local level to provide detailed reports on the performance of each hospital.

Data Envelopment Analysis (DEA) seems to be one of the most suitable methods for comparing the efficiency of various units providing healthcare services for several reasons, namely:

- Healthcare services are mainly public services that are always influenced by public policy (strategy) (e.g. by public expenditure programmes or through fiscal, legislative and other regulatory mechanisms).

- Public healthcare services are provided by various entities where each of them has its motives for providing the services and which are influenced by a whole range of different stakeholders (Rosenmayer, 2014). The results of this study are expected to be very beneficial to hospital managers, policy makers, local and central health authorities (e.g. Province Health Administration, Ministry of Health), researchers, healthcare professionals, and the public in general. For instance, based on DEA results, policy-makers may 
need to mobilise some of the resources from one province to another. They can use DEA results in decision-making processes involving resource planning, allocation, and utilisation. DEA can also be helpful in identifying medical resource deployment policies by information regarding the needs of the hospitals and in providing new insights on the distribution of health resources to hospitals that will have the highest potential to utilise these additional resources (Al-Shammari, 1999). By analysing output inefficiencies and excess inputs, managers can attempt to make hospital and health systems rational and efficient.

\section{References}

Afonso, A., \& St Aubyn, M. (2005). Nonparametric approaches to education and health efficiency in OECD countries. Journal of Applied Economics, 8(2), 227-246.

Al-Shammari, M. (1999). A multi-criteria data envelopment analysis model for measuring the productive efficiency of hospitals. International Journal of Operations \& Production Management, 19(9), 879-891. https://dx.doi. org/10.1108/01443579910280205.

Androniceanu, A., \& Ohanyan, G. (2016). Comparative approach on education and healthcare in Romania and Bulgaria as beneficiaries of the IMF financial assistance. Administrative and Public Management Review, 14(26), 25-48.

Barrientos, A., \& Boussofiane, A. (2005). How efficient are pension fund managers in Chile? Revista de Economia Contemporânea, 9(2), 289-311. https://dx.doi.org/10.1590/ S1415-98482005000200003.

Berg, S. (2010). Water utility benchmarking: Measurement, methodologies, and performance incentives. London: Iwa Publishing. https://dx.doi.org/10.2166/9781780401690.

Bhat, V. N. (2005). Institutional arrangements and efficiency of health care delivery systems. The European Journal of Health Economics, 6(3), 215222. https://dx.doi.org/10.1007/s10198-005-0294-1.

Bowlin, W. F. (1998). Measuring performance: An introduction to data envelopment analysis (DEA). The Journal of Cost Analysis, 15(2), 3-27. https://dx.doi.org/ 10.1080/08823871.1998.10462318.

Banxia Software. (2010). Frontier Analyst Software. Retrieved from www.banxia.com.

Charnes, A., Cooper, W. W., \& Rhodes, E. (1978). Measuring the efficiency of decision making units. European Journal of Operational Research, 2(6), 429-444. https://dx.doi. org/10.1016/0377-2217(78)90138-8.

Chirikos, T. N., \& Sear, A. M. (2000). Measuring hospital efficiency: A comparison of two approaches. Health Services Research, 34(6), 1389-1408.

Duguleana, L., \& Duguleana, C. (2015). Data Envelopment Analysis for the efficiency of Academic Departments. Bulletin of the Transilvania University of Brasov. Economic Sciences. Series V, 8(2), 453-468.

Emrouznejad, A., Parker, B. R., \& Tavares, G. (2008). Evaluation of research in efficiency and productivity: A survey and analysis of the first 30 years of scholarly literature in DEA. Socio-Economic Planning, 42(3), 151-157. https://dx.doi.org/10.1016/j.seps.2007.07.002.

Emrouznejad, A., Anouze, A. L., \& Thanassoulis, E. (2010). A semi-oriented radial measure for measuring the efficiency of decision making units with negative data, using DEA. European Journal of Operational Research, 200(1), 297-304. https://dx.doi. org/10.1016/j.ejor.2009.01.001.

Ersoy, K., Kavuncubasi, S., Ozcan, Y. A., \& Harris II, J. M. (1997). Technical efficiencies of Turkish hospitals: DEA approach. Journal of Medical Systems, 21(2), 67-74. https://doi. org/10.1023/A:1022801222540.

Fare, R., Grosskopf, S., \& HernandezSancho, F. (2004). Environmental performance: an index number approach. Resource and Energy Economics, 26(4), 343-352. https://dx.doi.org/10.1016/j.reseneeco.2003.10.003.

Farrell, M. J. (1957). The measurement of productive efficiency. Journal of the Royal Statistical Society. Series A (General), 120(3), 253-290. https://dx.doi.org/10.2307/2343100.

Fizel, J. L., \& Nunnikhoven, T. S. (1992). Technical efficiency of for-profit and non-profit nursing homes. Managerial and Decision Economics, 13(5), 429-439. https://dx.doi. org/10.1002/mde.4090130507.

Gapenski, L. C. (2012). Healthcare Finance: An Introduction to Accounting and Financial Management (5th ed.). Chicago: Health Administraion Press.

Gavurová, B., Kováč, V., \& Vagašová, T. (2017). Standardised mortality rate for cerebrovascular diseases in the Slovak Republic from 1996 to 2013 in the context of income inequalities and its international comparison. Health Economics Review, 7(7). 
https://dx.doi.org/10.1186/s13561-016-0140-4.

Gierulski, W. (2010). The method of data envelopment analysis as a tool for compiling a rating list. Operations Research and Decisions, 1, 41-59.

Grausová, M., Hužvár, M., \& Štrangfeldová, J. (2014). Healthcare systems efficiency in the Visegrád group. In AMSE 2014 Applications of Mathematics and Statistics in Economics. International Scientific Conference: Poland (pp. 104-113).

Grausová, M., \& Hužvár, M. (2016). Two views on efficiency of health expenditure in European countries assessed with DEA. In AMSE 2016 Applications of Mathematics and Statistics in Economics. International Scientific Conference: Slovakia (pp. 131-138).

Gruca, T. S., \& Nath, D. (2001). The technical efficiency of hospitals under a single payer system: the case of Ontario community hospitals. Health Care Management Science, 4(2), 91-101. https://doi.org/10.1023/A:1011401510010.

Guzik, B. (2009). Podstawowe modele DEA w badaniu efektywności gospodarczej i społecznej. Poznań: Wydawnictwo Uniwersytetu Ekonomicznego w Poznaniu.

Hadad, S., Hadad, Y., \& Simon-Tuval, T. (2013). Determinants of healthcare system's efficiency in OECD countries. The European Journal of Health Economics, 14(2), 253-265. https://doi.org/10.1007/s10198-011-0366-3.

Hass-Symotiuk, M. (2010). Conception of hospitals' reporting for integrated system of performance assessment. Szczecin: University of Szczecin.

Hofler, R. A., \& Rungeling, B. (1994). US nursing homes: Are they cost efficient? Economics Letters, 44(3), 301-305.

Hollingsworth, B., Dawson, P. J., \& Maniadakis, N. (1999). Efficiency measurement of health care: a review of non-parametric methods and applications. Health care management science, 2(3), 161-172. https://doi.org/10.1023/A:1019087828488.

Ivlev, I., Kneppo, P., \& Bartak, M. (2014). Multicriteria decision analysis: a multifaceted approach to medical equipment management. Technological and Economic Development of Economy, 20(3), 576-589. https://dx.doi.org/10. 3846/20294913.2014.943333.

Jacobs, R. (2001). Alternative methods to examine hospital efficiency: data envelopment analysis and stochastic frontier analysis. Health care management science, 4(2), 103-115. https://doi.org/10.1023/A:1011453526849.
Kaplan, R. S., \& Norton, D. P. (1992). The Balanced Scorecard measures that drive performance. Harvard Business Review, 70(1), 71-79.

Kludacz, M. (2012). Financial dimension of measurement and assessment in the model of performance card for the hospitals. In K. Matlaska \& M. Mokrys (Eds.), Proceedings of the Virtual International Conference on Advanced Research in Scientific Fields. Žilina: Publishing Institution of the University of Zilina

Kludacz-Alessandri, M. (2016). Non-financial dimensions of measurement and assessment in the performance model for hospitals. Managerial Economics, 17(1), 93-121. https://dx.doi. org/10.7494/manage.2016.17.1.93

Kooreman, P. (1994). Nursing home care in The Netherlands: A nonparametric efficiency analysis. Journal of Health Economics, 13(3), 301-316. https://dx.doi.org/10.1016/01676296(94)90029-9.

Kotsemir, M. N. (2013). Measuring national innovation systems efficiency-a review of DEA approach [Higher School of Economics Research Paper No. WP BRP, 16].

Kucharski, A. (2015). Efficiency of Using Research and Development Expenditures at Voivodship Level. Przedsiebiorczosc i Zarzadzanie, 16(1), 97-112. https://dx.doi. org/10.1515/eam-2015-0007.

Leggat, S. G., Narine, L., LemieuxCharles, L., Barnsley, J., Baker, G. R., Sicotte, C., Champagne, F., \& Bilodeau, H. (1998). A review of organizational performance assessment in health care. Health Services Management Research, 11(1), 3-18. https://dx.doi.org/10.1177/095148489801100102.

Linna, M., Hakkinen, U., \& Linakko, E. (1998). An econometric study of costs of teaching and research in Finnish hospitals. Health Economics, 7(5), 291-305. https://dx.doi.org/10.1002/ (SICI)1099-1050(199806)7:4\%3C291::AIDHEC343\%3E3.0.CO;2-4.

Marešová, P., Mohelská H., Dolejš, J., \& Kuča, K. (2015a). Socio-economic Aspects of Alzheimer's Disease. Current Alzheimer research, 12(9), 903-911. https://dx.doi.org/10. 2174/156720501209151019111448.

Marešová, P., Mohelská, H., \& Kuča, K. (2015b). Social and family load of Alzheimer's disease. Applied Economics, 48(21), 1936-1948. https://doi.org/10.1080/00036846.2015.1111986.

Nayar, P., \& Ozcan, Y. A. (2008). Data envelopment analysis comparison of hospital 
efficiency and quality. Journal of medical systems, 32(3), 193-199. https://dx.doi. org/10.1007/s10916-007-9122-8.

Nyman, J. A., \& Bricker, D. L. (1989). Profit incentives and technical efficiency in the production of nursing home care. The Review of Economics and Statistics, 71(4), 586-594. https://dx.doi.org/10.2307/1928100.

Nunamaker, T. R. (1983). Measuring routine nursing service efficiency: a comparison of cost per patient day and data envelopment analysis models. Health Services Research, 18(2), 183-205.

Olatubi, W. O., \& Dismukes, D. E. (2000). A data envelopment analysis of the levels and determinants of coal-fired electric power generation performance. Utilities Policy, 9(2), 47-59. https://dx.doi.org/10.1016/S0957-1787 (01)00004-2.

Palmer, S., \& Torgerson, D. J. (1999). Definitions of efficiency. British Medical Journal, 318(1136). https://doi.org/10.1136/ bmj.318.7191.1136.

Parkin, D., \& Hollingsworth, B. (1997). Measuring production efficiency of acute hospitals in Scotland, 1991-94: Validity issues in data envelopment analysis. Applied Economics, 29(11), 1425-1433. https://dx.doi. org/10.1080/000368497326255.

Rosenmayer, T. (2014). Using Data Envelopment Analysis: A Case of Universities. Review of Economic Perspectives, 14(1), 34-54. https://dx.doi.org/10.2478/revecp-2014-0003.

Rosko, M. D. (2001). Cost efficiency of US hospitals: A stochastic frontier approach. Health Economics, 10(6), 539-551. https://dx.doi. org/10.1002/hec.607.

Shaw, C. (2003). How can hospital performance be measured and monitored? Copenhagen: WHO Regional Office for Europe. Retrieved from http://www.euro.who. int/document/e82975.pdf.

Sherman, H. D. (1986). Managing productivity of health care organizations. New Directions for Program Evaluation, 1986(32), 31-46. https://dx.doi.org/10.1002/ev.1439.

Šoltés, M., \& Gavurová, B. (2014). Identification of the Functionality Level of Day Surgery in Slovakia. Ekonomický časopis, 62(10), 1031-1051.
Štefko, R., Gavurová, B., \& Koróny, S. (2016). Efficiency Measurement in Healthcare Work Management Using Malmquist Indices. Polish Journal of Management Studies, 13(1), 168-190. https://dx.doi.org/10.17512/ pjms.2016.13.1.16.

Vitaliano, D. F., \& Toren, M. (1996). Hospital cost and efficiency in a regime of stringent regulation. Eastern Economic Journal, 22(2), 161-175.

Worthington, A. C. (2004). Frontier efficiency measurement in health care: a review of empirical techniques and selected applications. Medical care research and review, 61(2), 135-170. https://dx.doi. org/10.1177/1077558704263796.

Yu, Y. (2014). Evaluation of R\&D effectiveness of small and medium-sized enterprises based on the DEA model. In 3rd International Conference on Science and Social Research (ICSSR 2014). Atlantis Press. https://dx.doi.org/10.2991/icssr-14.2014.121.

Zavras, A. I., Tsakos, G., Economou, C., \& Kyriopoulos, J. (2002). Using DEA to evaluate efficiency and formulate policy within a Greek national primary health care network. Journal of Medical Systems, 26(4), 285-292. https://doi. org/10.1023/A:1015860318972.

Zuckerman, S., Hadley, J., \& lezzoni, L. (1994). Measuring hospital efficiency with frontier cost functions. Journal of Health Economics, 13(3), 255-280. https://dx.doi. org/10.1016/0167-6296(94)90027-2.

Assoc. Prof. Kristina Kocisova, PhD. Technical University of Kosice Faculty of Economics Slovakia kristina.kocisova@tuke.sk

Prof. dr hab. Maria Hass-Symotiuk The Jacob of Paradies University Poland maria.hass-symotiuk@wp.pl

Magdalena Kludacz-Alessandri, Ph.D. Warsaw University of Technology The College of Economics and Social Sciences in Plock Poland m.kludacz@pw.plock.pl 


\section{Abstract}

\section{USE OF THE DEA METHOD TO VERIFY THE PERFORMANCE MODEL FOR HOSPITALS}

\section{Kristina Kocisova, Maria Hass-Symotiuk, Magdalena Kludacz-Alessandri}

This paper employs the method of data envelopment analysis (DEA) to compare the relative efficiency of Polish hospitals in meso perspective. It means that the indicators selected to measure the performance of hospitals were aggregated at the regional level (a level of 16 Polish provinces). As the hospitals are a critical part of the healthcare system, they are increasingly the subject of analyses aimed at defining, measuring, and improving their performance. Therefore, in the methodology part, we present the DEA as the method for efficiency measurement together with its advantages and limitations. The study attempts to find out which provinces can be used as models and illustrated the areas where inefficient units need to be improved. The hospital input measures included are the Average time of hospitalisation (in days), Average costs of day hospital treatment. The output measures included are the Average number of patients per bed per year, the Share of accredited hospitals as a proportion of the number of all hospitals, net profit per physician. The DEA models are solved using the computer program Frontier Analyst, Version 4. We found that five provinces were efficient and eleven were not, where the efficiency score varied from $76.2 \%$ to $100 \%$. Provinces such as Lower Silesia Province, Lublin Province, Lubuskie Province, Świętokrzyskie Province, and Warmia-Masuria Province were the best performers in that they maximised both quantitative and qualitative outcomes. The identification of the strongest and the weakest within provinces could be beneficial in improving the efficiency and performance of the hospitals. The result identifies the inefficient provinces that can improve their efficiency by making the efficient provinces as their role model. This paper is the first published study that benchmarks the performance of healthcare services in Poland.

Key Words: Performance model, Polish hospitals, DEA analysis, efficiency.

JEL Classification: I18, M41.

DOI: 10.15240/tul/001/2018-4-009 